\title{
Non dimensional analysis of axially polarized passive magnetic bearings
}

\author{
Mintu Karmakar $^{1}$ (D) Susenjit Sarkar ${ }^{1}$
}

Received: 9 October 2019 / Accepted: 22 April 2020 / Published online: 29 April 2020

(c) Springer Nature Switzerland AG 2020

\begin{abstract}
Ranges of investigation on passive magnetic bearing exist where radial and axial forces and variations of a few coefficients of radial and axial stiffnesses are shown for a particular set of chosen parameters and dimensions. The paper presents a non-dimensional approach for the same with additional parameters like all coefficients of stiffnesses and natural frequency. The model is considered for static analysis of axially polarised ring shaped magnets for both stator and rotor part in three degrees of freedom with three linear translations in 3D Cartesian coordinate system. The significance of this non-dimensional method is more generalised to the designer where boundary parameters like maximum force on the rotor of passive magnetic bearing, natural frequency, etc. can be easily estimated by simple conversion without doing separate numerical simulation for different parameters every time. The analysis of additional parameters like non-dimensional natural frequency can be the input for non-dimensional dynamic analysis. This paper also provides a way for maximization of radial force with the optimized solution of physical dimensions of passive magnetic bearing as inner radius of stator and outer radius of rotor magnet while keeping others as input parameters. The proposed model is validated with data available for radial and axial forces as well as for radial and axial stiffnesses that found in existing literature for similar kind of problem.
\end{abstract}

Keywords Non-dimensional · Passive magnetic bearing $\cdot$ Radial force maximization $\cdot$ Natural frequency $\cdot$ Axially polarised

\begin{tabular}{|c|c|}
\hline & \\
\hline & Magnetic force between stator and rotor $(\mathrm{N})$ \\
\hline & Absolute permeability $\left(4 \pi \times 10^{-7} \frac{\mathrm{N}}{\mathrm{A}^{2}}\right.$ or $\frac{\mathrm{H}}{\mathrm{m}}$ or $\left.\frac{T \mathrm{~m}}{\mathrm{~A}}\right)$ \\
\hline & 3.1415926535 (Non-dimensional) \\
\hline & $\begin{array}{l}\text { Magnetic pole strength of stator magnet (Wb or } \\
\text { Am) }\end{array}$ \\
\hline & $\begin{array}{l}\text { Magnetic pole strength of rotor magnet (Wb or } \\
\text { Am) }\end{array}$ \\
\hline & $\begin{array}{l}\text { Distance between stator and rotor magnetic pole } \\
(\mathrm{m})\end{array}$ \\
\hline & Stator magnetic surface charge density $(\mathrm{T})$ \\
\hline & netic surface charge density $(T)$ \\
\hline & gnetic pole surface area per pole $\left(\mathrm{m}^{2}\right)$ \\
\hline & netic pole surface area per pole ( $n$ \\
\hline
\end{tabular}

\section{Abbreviations}

$\mathrm{F}_{\mathrm{sr}} \quad$ Magnetic force between stator and rotor $(\mathrm{N})$

$\mu_{0} \quad$ Absolute permeability $\left(4 \pi \times 10^{-7} \frac{\mathrm{N}}{\mathrm{A}^{2}}\right.$ or $\frac{\mathrm{H}}{\mathrm{m}}$ or $\left.\frac{T m}{\mathrm{~A}}\right)$

$\pi \quad 3.1415926535$ (Non-dimensional)

$\mathrm{q}_{\mathrm{s}} \quad$ Magnetic pole strength of stator magnet (Wb or Am Am) (m)

Stator magnetic surface charge density $(T)$

$\mathrm{Br}_{1} \quad$ Residual magnetism of rotor magnetic material ( $\mathrm{T}$ )

$\mathrm{Br}_{2}$ Residual magnetism of stator magnetic material (T)

$\mathrm{r}_{1} \quad$ Radial distance of rotor small elemental area $\mathrm{dS}_{\mathrm{r}}$ from rotor axis $(\mathrm{m})$

$r_{2}$ Radial distance of stator small elemental area $\mathrm{dS}_{\mathrm{s}}$ from stator axis (m)

a Angular displacement of stator small elemental area $\mathrm{dS}_{\mathrm{s}}$ about stator axis measured from $\mathrm{x}$ axis (radian)

$\beta \quad$ Angular displacement of rotor small elemental area $\mathrm{dS}_{\mathrm{r}}$ about rotor axis measured from $\mathrm{x}$ axis (radian)

Mintu Karmakar, mintukarmakar@gmail.com; Susenjit Sarkar, susenjit_s@rediffmail.com | ${ }^{1}$ Department of Mechanical Engineering, Jadavpur University, Kolkata, West Bengal 700032, India. 
x Radial displacement of rotor centroid from stator centroid (global origin) along $x$ axis (m)

y Radial displacement of rotor centroid from stator centroid (global origin) along y axis (m)

z Axial displacement of rotor centroid from stator centroid (global origin) along $z$ axis (m)

$\mathrm{u} \quad$ Radial displacement of rotor small elemental area $\mathrm{dS}_{\mathrm{r}}$ from stator small elemental area $\mathrm{dS}_{\mathrm{s}}$ along $\mathrm{x}$ axis (m)

$v \quad$ Radial displacement of rotor small elemental area $\mathrm{dS}_{\mathrm{r}}$ from stator small elemental area $\mathrm{dS}_{\mathrm{s}}$ along y axis (m)

$\mathrm{z}_{1} \quad$ Displacement of small elemental area $\mathrm{dS}_{\mathrm{r}}$ of rotor's South Pole from small elemental area $\mathrm{dS}_{\mathrm{s}}$ of stator's North Pole along $z$ axis (m)

$z_{2} \quad$ Displacement of small elemental area $\mathrm{dS}_{\mathrm{r}}$ of rotor's North Pole from small elemental area $\mathrm{dS}_{\mathrm{s}}$ of stator's South Pole along $z$ axis (m)

$z_{3} \quad$ Displacement of small elemental area $\mathrm{dS}_{\mathrm{r}}$ of rotor's North Pole from small elemental area $\mathrm{dS}_{\mathrm{s}}$ of stator's North Pole along $z$ axis (m)

$z_{4} \quad$ Displacement of small elemental area $\mathrm{dS}_{\mathrm{r}}$ of rotor's South Pole from small elemental area $\mathrm{dS}_{\mathrm{s}}$ of stator's South Pole along $z$ axis (m)

$\mathrm{L}_{\mathrm{s}} \quad$ Stator length along stator $\mathrm{z}$ axis $(\mathrm{m})$

$\mathrm{L}_{\mathrm{r}} \quad$ Rotor length along stator $\mathrm{z}$ axis $(\mathrm{m})$

$\delta \quad$ Maximum radial clearance between rotor and stator cylindrical axis $(\mathrm{m})$

$\mathrm{F}_{\text {ref }} \quad$ Reference force of rotor and stator magnets (N)

$\mathrm{F}_{\mathrm{x}} \quad$ Magnetic force along $\mathrm{x}$ axis $(\mathrm{N})$

$\mathrm{F}_{0} \quad$ External radial force per bearing applied on journal having rotor $(\mathrm{N})$

$\mathrm{R}_{1} \quad$ Inner radius of rotor magnet $(\mathrm{m})$

$\mathrm{R}_{2} \quad$ Outer radius of rotor magnet (m)

$\mathrm{R}_{3} \quad$ Inner radius of stator magnet $(\mathrm{m})$

$\mathrm{R}_{4} \quad$ Outer radius of stator magnet $(\mathrm{m})$

$\mathrm{k} \quad$ Position stiffness $\left(\frac{N}{m}\right)$

$\mathrm{k}_{\mathrm{xx}} \quad$ Position stiffness when variation of force and displacement both along $\mathrm{x}$ axis $\left(\frac{\mathrm{N}}{\mathrm{m}}\right)$

$k_{y y} \quad$ Position stiffness when variation of force and displacement both along y axis $\left(\frac{N}{m}\right)$

$\mathrm{k}_{\mathrm{zz}} \quad$ Position stiffness when variation of force and displacement both along $\mathrm{z}$ axis $\left(\frac{\mathrm{N}}{\mathrm{m}}\right)$

$k_{x y} \quad$ Position stiffness when variation of force along $x$ axis and variation of displacement along $y$ direction $\left(\frac{N}{m}\right)$

$\mathrm{k}_{\mathrm{yx}} \quad$ Position stiffness when variation of force along $\mathrm{y}$ axis and variation of displacement along $\mathrm{x}$ direc$\operatorname{tion}\left(\frac{N}{m}\right)$ $k_{x z} \quad$ Position stiffness when variation of force along $x$ axis and variation of displacement along $z$ direc$\operatorname{tion}\left(\frac{N}{m}\right)$

$\mathrm{k}_{\mathrm{zx}} \quad$ Position stiffness when variation of force along $\mathrm{z}$ axis and variation of displacement along $x$ direc$\operatorname{tion}\left(\frac{N}{m}\right)$

$\mathrm{k}_{\mathrm{yz}} \quad$ Position stiffness when variation of force along $\mathrm{y}$ axis and variation of displacement along $z$ direc$\operatorname{tion}\left(\frac{N}{m}\right)$

$\mathrm{k}_{\mathrm{zy}} \quad$ Position stiffness when variation of force along $\mathrm{z}$ axis and variation of displacement along y direc$\operatorname{tion}\left(\frac{N}{m}\right)$

$\omega \quad$ Frequency $(\mathrm{rad} / \mathrm{s})$

m Mass $(\mathrm{kg})$

$\varphi_{\mathrm{x}} \quad$ Amplitude of displacement along $\mathrm{x}$ axis (m)

$\varphi_{y} \quad$ Amplitude of displacement along y axis (m)

$\varphi_{\mathrm{z}} \quad$ Amplitude of displacement along $\mathrm{z}$ axis (m)

e 2.71828 (Non-dimensional)

$\mathrm{t} \quad$ Time (s)

$\omega_{\text {ref }}$ Reference natural frequency (rad/s)

$\mathrm{S}$ Force ratio (Non-dimensional)

$a_{r} \quad$ Frequency that governs growth of vibration ( $\mathrm{rad} / \mathrm{s}$ )

$\omega_{r} \quad$ Natural frequency ( $\mathrm{rad} / \mathrm{s}$ )

$\mathrm{N}_{\mathrm{x}} \quad$ Number of space discretisation along $\mathrm{x}$ axis (Non-dimensional)

$\mathrm{N}_{\mathrm{y}} \quad$ Number of space discretisation along y axis (Non-dimensional)

$\mathrm{N}_{\mathrm{z}} \quad$ Number of space discretisation along $\mathrm{z}$ axis (Non-dimensional)

\section{Introduction}

In recent past, there are less numbers of available research papers on passive magnetic bearings in comparison to active magnetic bearings. Lower magnetic strength and instability of passive magnetic bearings, kept the researchers in abeyance for further development. Research on passive magnetic bearings was started using basic study of permanent magnets for radial and axial forces [1]. Yung et al. [2] derived the equation of force between two small magnetic dipoles smaller than their separation using Taylor expansion for the first non-zero term by vector differential and path integral derivation approaches. Simon et al. [3] in their paper, discussed about spin stabilization of magnetic levitating top on magnetic base. Gyroscopic precession around local magnetic field was considered to predict maximum stable spin speed of the top. Tan et al. [4] discussed about hybrid type of bearing. They used passive magnetic bearing in the experimental test rig of hydrodynamic journal bearing to study the magnetic forces during 
starting and stopping of the machine. Muzakkir et al. [5] hybridized a magnetic arrangement in conventional journal bearing system to do feasibility study in heavy load and low speed conditions. They calculated magnetic levitation force theoretically to find the reasons for mechanical contact between rotor and stator magnets. Different components of hybrid magnet bearing models were presented by Mukhopadhyay et al. [6]. Vertical instability of repulsive type magnetic bearing system was controlled by using micro controllers. Azukuzawa and Yamamoto [7] considered a pair of ring shaped axially polarized permanent magnets as a magnetic top levitating on larger ring shaped permanent magnet rested at the bottom. They investigated design parameters for levitation and simulate the behaviour of levitating magnetic top. The optimization of repulsive forces was a carried out for multi-layered permanent magnets by Moser et al. [8]. There was also relevant research on flux density produced by axially polarised passive magnetic bearing [9]. Methods of estimation of forces and stiffness of passive magnetic bearings (both radially and axially polarised type) were proposed by many researchers [10-21]. Janssen et al. [22] derived analytical force and stiffness expressions for the cases where the conventional analytical expressions are difficult to solve. They also proposed the analytical stiffness matrix which is necessary for the design and analysis of such magnetic bearings. Another relevant research on demagnetising field [23] and diamagnetic levitation [24] also advances the magnetic bearing research. Some researcher also reviewed comparison of magnetic bearings over ball bearings [25] and suggested the improvement of the performance of passive magnetic bearing using experimental investigation. To achieve less computational time for calculating force between rotor and stator of passive magnetic bearing some researchers tried various statistical approaches like Monte Carlo integration technique etc. in recent years [26-28].

It is found from previous literature that with the progress of research, non-dimensional model approach for calculating forces and stiffness of axially polarised ring type passive magnetic bearing was not exploited so far. Non-dimensional analysis is essential to reduce the dependency of the parameters and units of the parameters. Once non-dimensional generalised relationship is found it is easy and fast for calculating customised set of parameters and unit system. In this paper, non-dimensional modelling approach is adopted to find out optimized design parameters of rotor and stator part of the bearing. The non-dimensional model is validated after converting it in dimensional model and comparing with previous dimensional research data which are already reported in various research papers. Non-dimensional natural frequency of the passive magnetic bearing system is also simulated in this model. Here ring shaped magnets are used in rotor and stator. Stator magnet is attached with static frame of bearing house, while rotor magnet is attached to axial end of journal. Stator magnet has zero degree of freedom. But the rotor magnet can rotate or translate with the shaft, but with no relative motion in between them. Force, stiffness, natural frequency, stability, etc. are important for static and dynamic analyses.

\section{Configuration details for the proposed model}

\subsection{Passive magnetic bearing set up}

Two pairs of permanent ring type stator and rotor magnets are attached to bearing house of fixed reference and journal axial end respectively. The assembly set up and schematic representations for analytical derivation purposes are shown in Fig. 1a, b.

In Fig. 1a partially exploded view of model is shown in simple form where ring types of bushes are shown with the rotor magnet. This is just for axial shift alignment with the stator position. The stator magnet is assumed stationery at the bearing house arrangement by any type of fixed joining with the housing. The rotor magnet is also assumed fixed with journal shaft so that there has no relative rotation or translation between magnet and the journal shaft. In Fig. $1 \mathrm{~b}$ the schematic representation for analytic derivation is shown. Almost similar type of sketch is already reported by Lijesh and Hirani [21] and Santra et al. [26-28]. In this Fig. $1 \mathrm{~b}$ the relative axial shift of rotor magnet by $z$ unit is shown in section $A-A$. Section line passing through centre of rotor is drawn from same figure in side view $B$. As for example $z=15$ unit is considered for axial shift of the rotor magnet. Similarly other values of different parameters are assumed as reference purpose only. Radial shift can be shown in view B of same Fig. 1b. Outer and inner radius for rotor and stator are shown in this view $B$ in the same figure. Radial shift of rotor centre in direction of $x$ and $y$ with respect to stator cylindrical axes are shown in enlarged scale in detail $C$ of Fig. $1 \mathrm{~b}$. Small arbitrary elemental area in rotor cross section at $r_{1}$ radius and angle $\beta$ measured from rotor centre in counter clock wise direction is shown in detail $C$ which is cropped from view $B$ of same Fig. 1b. Similarly another elemental area from stator cross section at $r_{2}$ radius and angle $\alpha$ measured from stator axis in counter clock wise direction is shown in detail $\mathrm{C}$ of Fig. $1 \mathrm{~b}$. Relative displacement of rotor small elemental area and stator small elemental area in $\mathrm{x}$ and $\mathrm{y}$ direction are shown as $\mathrm{X}$ and $\mathrm{Y}$. 
Fig. 1 a Partial exploded view of passive magnetic bearing set up, b A schematic representation for analytical derivation (a)

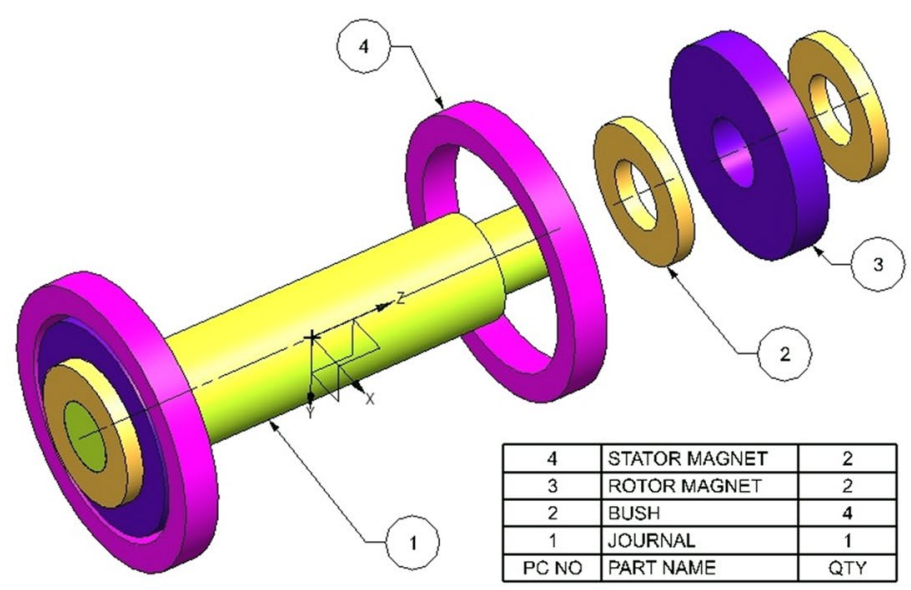

(b)

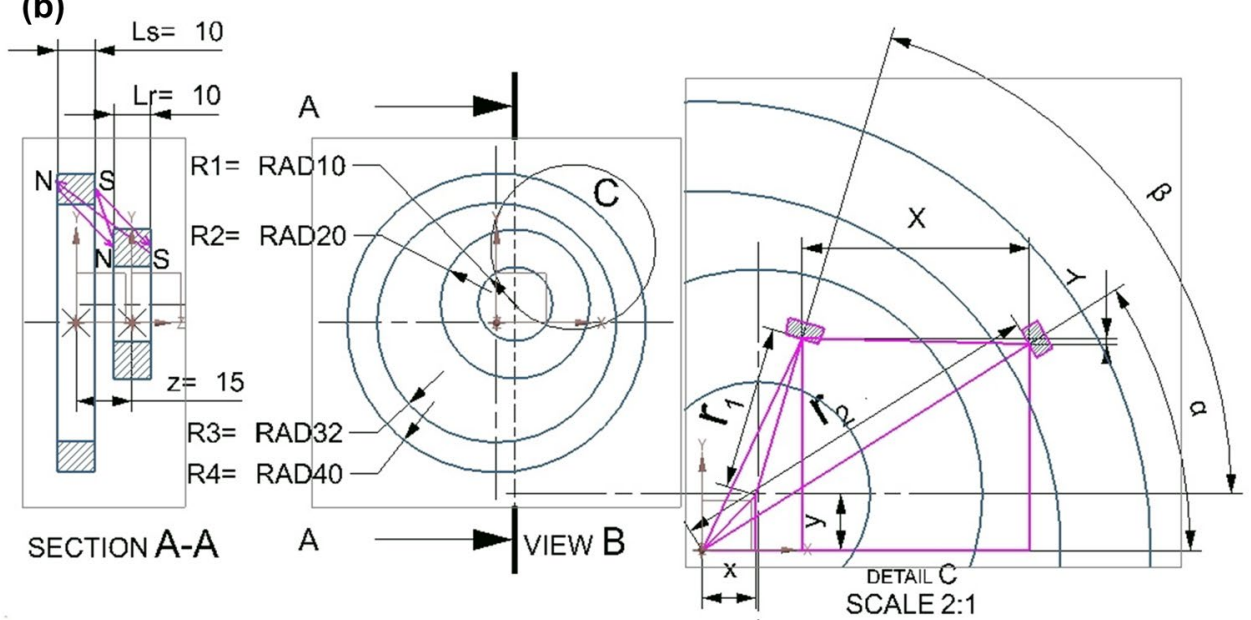

\subsection{General assumption and consideration}

The following assumption is considered for the proposed model.

I. Both of stator and rotor magnet pair is axially magnetized ring magnet.

II. Stator magnets are aligned with the common bearing axis of fixed reference.

III. The magnet material is hard, ferromagnetic and isotropic.

IV. The present analysis is static analysis.

V. Demagnetization is not considered.

VI. Shaft is rigid and massless.

VII. Nominal mass of rotor/disc is considered for the purpose of analysis.

VIII. Finite division approach has been taken care for this method.

IX. Combination of Riemann summation and triple integral is considered for fourth dimensional integration.
X. Flat surface magnetic charge density is considered constant over flat surface of both magnets.

$X I$. Horizontal $X$ and vertical $Y$ are radial directions and axial $Z$ translation of rotor magnet is considered for the analysis.

XII. The rotors have common angular spin velocity with respect to own axis aligned with journal axis along $Z$ direction.

XIII. Columbian model for evaluation of magnetic force is considered.

\subsection{Columbian model of magnetic force}

The magnetic force of the Columbian model described by Santra et al. [26-28] is rearranged below as

$\overrightarrow{d F_{s r}}=\frac{\mu_{0}}{4 \pi} \times \frac{q_{s} \times q_{r}}{r_{s r}^{3}} \overrightarrow{r_{s r}}$ 
$q_{s}=\sigma_{s} d S_{s}, q_{r}=\sigma_{r} d S_{r}, \sigma_{r}=\frac{B r_{1}}{\mu_{0}} \sigma_{s}=\frac{B r_{2}}{\mu_{0}}$

$d S_{s}=r_{2} \times d \alpha \times d r_{2}, d S_{r}=r_{1} \times d \beta \times d r_{1}$

$\overrightarrow{d F_{s r}}=\frac{B r_{1} \times B r_{2}}{4 \pi \mu_{0}} \times \frac{r_{1} r_{2} d r_{1} d r_{2} d \alpha d \beta}{r_{s r}^{3}} \overrightarrow{r_{s r}}$

\subsection{Non-dimensional approach of parameters}

All parameters have been converted to non-dimensional ones by dividing by maximum radial clearance $(\delta)$. The maximum radial clearance $(\delta)$ is a geometric parameter of the rotor and stator magnet, which is evaluated by subtraction of outer radius of rotor magnet $\left(R_{2}\right)$ from inner radius of stator magnet $\left(\mathrm{R}_{3}\right)$. These two radii are also geometric parameters of bearing system. From the sketch detail C of Fig. 1b, we can write

$$
\begin{aligned}
& u=x+r_{1} \cos \beta-r_{2} \cos \alpha \\
& v=y+r_{1} \sin \beta-r_{2} \sin \alpha \\
& z_{1}=z+0.5 \times\left(L_{s}+L_{r}\right) \\
& z_{2}=z-0.5 \times\left(L_{s}+L_{r}\right) \\
& z_{3}=z+0.5 \times\left(L_{s}-L_{r}\right) \\
& z_{4}=z-0.5 \times\left(L_{s}-L_{r}\right)
\end{aligned}
$$

where, $u, v, z_{1}, z_{2}, z_{3}$ and $z_{4}$ are relative displacements of rotor elemental area from that of stator one. Refer notations in Abbreviation section of the paper for further understanding.

Dividing above Eqs. (5 to 10 ) by maximum radial clearance $\left(\delta=R_{3}-R_{2}\right)$, we have

$\bar{u}=\bar{x}+\bar{r}_{1} \cos \beta-\bar{r}_{2} \cos \alpha$

$\bar{v}=\bar{y}+\bar{r}_{1} \sin \beta-\bar{r}_{2} \sin \alpha$

$\bar{z}_{1}=\bar{z}+0.5 \times\left(\bar{L}_{s}+\bar{L}_{r}\right)$

$\bar{z}_{2}=\bar{z}-0.5 \times\left(\bar{L}_{s}+\bar{L}_{r}\right)$

$\bar{z}_{3}=\bar{z}+0.5 \times\left(\bar{L}_{s}-\bar{L}_{r}\right)$

$\bar{z}_{4}=\bar{z}-0.5 \times\left(\bar{L}_{s}-\bar{L}_{r}\right)$

Above parameters are non dimensionalized and represented with a bar'-' above the usual notations.

Again reference force in rotor and stator magnets is written as

$F_{\text {ref }}=\frac{B r_{1} \times B r_{2} \times \delta^{2}}{4 \pi \mu_{0}}$

By dividing magnetic force along $x$-axis $\left(F_{x}\right)$ by reference force $\left(\mathrm{F}_{\text {ref }}\right)$ we have non dimensionalized magnetic force $\bar{F}_{x}=\frac{F_{x}}{F_{r e f}}$

Expanding Eq. (18),

$$
\begin{aligned}
\bar{F}_{x}= & \int_{\bar{R}_{3}}^{\bar{R}_{4}} \int_{\bar{R}_{1}}^{\bar{R}_{2}} \int_{0}^{2 \pi} \int_{0}^{2 \pi} \bar{r}_{1} \times \bar{r}_{2} \times \bar{u} \times\left[-\frac{1}{\left(\bar{u}^{2}+\bar{v}^{2}+\bar{z}_{1}^{2}\right)^{\frac{3}{2}}}-\frac{1}{\left(\bar{u}^{2}+\bar{v}^{2}+\bar{z}_{2}^{2}\right)^{\frac{3}{2}}}+\frac{1}{\left(\bar{u}^{2}+\bar{v}^{2}+\bar{z}_{3}^{2}\right)^{\frac{3}{2}}}+\frac{1}{\left(\bar{u}^{2}+\bar{v}^{2}+\bar{z}_{4}^{2}\right)^{\frac{3}{2}}}\right] \\
& \times \overline{d r_{1}} \times \overline{d r_{2}} \times d \alpha \times d \beta
\end{aligned}
$$

Similarly we can get other non-dimensional forces $\left(\bar{F}_{y}\right)$ and $\left(\bar{F}_{z}\right)$ as

$$
\begin{aligned}
\bar{F}_{y}= & \int_{\bar{R}_{3}}^{\bar{R}_{4}} \int_{\bar{R}_{1}}^{\bar{R}_{2}} \int_{0}^{2 \pi} \int_{0}^{2 \pi} \bar{r}_{1} \times \bar{r}_{2} \times \bar{v} \times\left[-\frac{1}{\left(\bar{u}^{2}+\bar{v}^{2}+\bar{z}_{1}^{2}\right)^{\frac{3}{2}}}-\frac{1}{\left(\bar{u}^{2}+\bar{v}^{2}+\bar{z}_{2}^{2}\right)^{\frac{3}{2}}}+\frac{1}{\left(\bar{u}^{2}+\bar{v}^{2}+\bar{z}_{3}^{2}\right)^{\frac{3}{2}}}+\frac{1}{\left(\bar{u}^{2}+\bar{v}^{2}+\bar{z}_{4}^{2}\right)^{\frac{3}{2}}}\right] \\
& \times \overline{d r_{1}} \times \overline{d r_{2}} \times d \alpha \times d \beta
\end{aligned}
$$


And

$$
\begin{aligned}
\bar{F}_{z} & =\int_{\bar{R}_{3}}^{\bar{R}_{4}} \int_{\bar{R}_{1}}^{\bar{R}_{2}} \int_{0}^{2 \pi} \int_{0}^{2 \pi} \bar{r}_{1} \times \bar{r}_{2} \times\left[-\frac{\bar{z}_{1}}{\left(\bar{u}^{2}+\bar{v}^{2}+\bar{z}_{1}^{2}\right)^{\frac{3}{2}}}-\frac{\bar{z}_{2}}{\left(\bar{u}^{2}+\bar{v}^{2}+\bar{z}_{2}^{2}\right)^{\frac{3}{2}}}+\frac{\bar{z}_{3}}{\left(\bar{u}^{2}+\bar{v}^{2}+\bar{z}_{3}^{2}\right)^{\frac{3}{2}}}+\frac{\bar{z}_{4}}{\left(\bar{u}^{2}+\bar{v}^{2}+\bar{z}_{4}^{2}\right)^{\frac{3}{2}}}\right] \\
& \times \overline{d r_{1}} \times \overline{d r_{2}} \times d \alpha \times d \beta
\end{aligned}
$$

Since force from each bearing applied on journal is $F_{0}$, we can write non dimensional stiffness as

$k_{x x}=\frac{F_{r e f}}{\delta} \times \bar{k}_{x x}^{\prime}$

$\bar{k}_{x x}=\frac{\delta}{F_{0}} \times k_{x x}$

where $\bar{k}_{x x}^{\prime}=\frac{\partial \bar{F}_{x}}{\partial \bar{x}}$

so,

where $\left(F_{0} / \delta\right)$ is reference stiffness.

Again,

$\bar{k}_{x x}=\frac{F_{r e f}}{F_{0}} \times \bar{k}_{x x}^{\prime}$

$k_{x x}=\frac{\partial F_{x}}{\partial x}$

or,

since $k_{\text {ref }}=\frac{F_{0}}{\delta}$

Again non dimensional stiffness of second kind can be written in partial derivative form as

$k_{x x}=\frac{F_{r e f}}{\delta} \frac{\partial \bar{F}_{x}}{\partial \bar{x}}$

(24) $\bar{k}_{x x}^{\prime}=\frac{\partial \bar{F}_{x}}{\partial \bar{u}} \frac{\partial \bar{u}}{\partial \bar{x}}$

or,

Therefore, using Eqs. (11) and (19), we have

$$
\begin{aligned}
\bar{k}_{x x}^{\prime}= & \int_{\bar{R}_{3}}^{\bar{R}_{4}} \int_{\bar{R}_{1}}^{\bar{R}_{2}} \int_{0}^{2 \pi} \int_{0}^{2 \pi} \bar{r}_{1} \times \bar{r}_{2} \times\left[\left\{-\frac{1}{\left(\bar{u}^{2}+\bar{v}^{2}+\bar{z}_{1}^{2}\right)^{\frac{3}{2}}}-\frac{1}{\left(\bar{u}^{2}+\bar{v}^{2}+\bar{z}_{2}^{2}\right)^{\frac{3}{2}}}+\frac{1}{\left(\bar{u}^{2}+\bar{v}^{2}+\bar{z}_{3}^{2}\right)^{\frac{3}{2}}}+\frac{1}{\left(\bar{u}^{2}+\bar{v}^{2}+\bar{z}_{4}^{2}\right)^{\frac{3}{2}}}\right\}-3 \bar{u}^{2}\right. \\
& \left.\times\left\{-\frac{1}{\left(\bar{u}^{2}+\bar{v}^{2}+\bar{z}_{1}^{2}\right)^{\frac{5}{2}}}-\frac{1}{\left(\bar{u}^{2}+\bar{v}^{2}+\bar{z}_{2}^{2}\right)^{\frac{5}{2}}}+\frac{1}{\left(\bar{u}^{2}+\bar{v}^{2}+\bar{z}_{3}^{2}\right)^{\frac{5}{2}}}+\frac{1}{\left(\bar{u}^{2}+\bar{v}^{2}+\bar{z}_{4}^{2}\right)^{\frac{5}{2}}}\right\}\right] \\
& \times \overline{d r_{1}} \times \overline{d r_{2}} \times d \alpha \times d \beta
\end{aligned}
$$

$$
\begin{aligned}
\bar{k}_{y y}^{\prime}= & \int_{\bar{R}_{3}}^{\bar{R}_{4}} \int_{\bar{R}_{1}}^{\bar{R}_{2}} \int_{0}^{2 \pi} \int_{0}^{2 \pi} \bar{r}_{1} \times \bar{r}_{2} \times\left[\left\{-\frac{1}{\left(\bar{u}^{2}+\bar{v}^{2}+\bar{z}_{1}^{2}\right)^{\frac{3}{2}}}-\frac{1}{\left(\bar{u}^{2}+\bar{v}^{2}+\bar{z}_{2}^{2}\right)^{\frac{3}{2}}}+\frac{1}{\left(\bar{u}^{2}+\bar{v}^{2}+\bar{z}_{3}^{2}\right)^{\frac{3}{2}}}+\frac{1}{\left(\bar{u}^{2}+\bar{v}^{2}+\bar{z}_{4}^{2}\right)^{\frac{3}{2}}}\right\}-3 \bar{v}^{2}\right. \\
& \left.\times\left\{-\frac{1}{\left(\bar{u}^{2}+\bar{v}^{2}+\bar{z}_{1}^{2}\right)^{\frac{5}{2}}}-\frac{1}{\left(\bar{u}^{2}+\bar{v}^{2}+\bar{z}_{2}^{2}\right)^{\frac{5}{2}}}+\frac{1}{\left(\bar{u}^{2}+\bar{v}^{2}+\bar{z}_{3}^{2}\right)^{\frac{5}{2}}}+\frac{1}{\left(\bar{u}^{2}+\bar{v}^{2}+\bar{z}_{4}^{2}\right)^{\frac{5}{2}}}\right\}\right] \\
& \times \overline{d r_{1}} \times \overline{d r_{2}} \times d \alpha \times d \beta
\end{aligned}
$$

Similarly other non-dimensional stiffnesses of second kind coefficients can be found as 


$$
\begin{aligned}
\bar{k}_{\mathrm{zz}}^{\prime}= & \int_{\bar{R}_{3}}^{\bar{R}_{4}} \int_{\bar{R}_{1}}^{\bar{R}_{2}} \int_{0}^{2 \pi} \int_{0}^{2 \pi} \bar{r}_{1} \times \bar{r}_{2} \times\left[\left\{-\frac{1}{\left(\bar{u}^{2}+\bar{v}^{2}+\bar{z}_{1}^{2}\right)^{\frac{3}{2}}}-\frac{1}{\left(\bar{u}^{2}+\bar{v}^{2}+\bar{z}_{2}^{2}\right)^{\frac{3}{2}}}+\frac{1}{\left(\bar{u}^{2}+\bar{v}^{2}+\bar{z}_{3}^{2}\right)^{\frac{3}{2}}}+\frac{1}{\left(\bar{u}^{2}+\bar{v}^{2}+\bar{z}_{4}^{2}\right)^{\frac{3}{2}}}\right\}-3\right. \\
& \left.\times\left\{-\frac{1}{\left(\bar{u}^{2}+\bar{v}^{2}+\bar{z}_{1}^{2}\right)^{\frac{5}{2}}}-\frac{1}{\left(\bar{u}^{2}+\bar{v}^{2}+\bar{z}_{2}^{2}\right)^{\frac{5}{2}}}+\frac{1}{\left(\bar{u}^{2}+\bar{v}^{2}+\bar{z}_{3}^{2}\right)^{\frac{5}{2}}}+\frac{1}{\left(\bar{u}^{2}+\bar{v}^{2}+\bar{z}_{4}^{2}\right)^{\frac{5}{2}}}\right\}\right] \\
& \times \overline{d r} r_{1} \times \overline{d r_{2}} \times d \alpha \times d \beta
\end{aligned}
$$

$$
\begin{aligned}
& \bar{k}_{x y}^{\prime}=\int_{\bar{R}_{3}}^{\bar{R}_{4}} \int_{\bar{R}_{1}}^{\bar{R}_{2}} \int_{0}^{2 \pi} \int_{0}^{2 \pi} 3 \times \bar{r}_{1} \times \bar{r}_{2} \times \bar{u} \times \bar{v} \times\left\{\frac{1}{\left(\bar{u}^{2}+\bar{v}^{2}+\bar{z}_{1}^{2}\right)^{\frac{5}{2}}}\right. \\
& \left.+\frac{1}{\left(\bar{u}^{2}+\bar{v}^{2}+\bar{z}_{2}^{2}\right)^{\frac{5}{2}}}-\frac{1}{\left(\bar{u}^{2}+\bar{v}^{2}+\bar{z}_{3}^{2}\right)^{\frac{5}{2}}}-\frac{1}{\left(\bar{u}^{2}+\bar{v}^{2}+\bar{z}_{4}^{2}\right)^{\frac{5}{2}}}\right\} \times \overline{d r_{1}} \times \overline{d r_{2}} \times d \alpha \times d \beta \\
& \bar{k}_{y z}^{\prime}=\int_{\bar{R}_{3}}^{\bar{R}_{4}} \int_{\bar{R}_{1}}^{\bar{R}_{2}} \int_{0}^{2 \pi} \int_{0}^{2 \pi} 3 \times \bar{r}_{1} \times \bar{r}_{2} \times \bar{v} \times\left\{\frac{\bar{z}_{1}}{\left(\bar{u}^{2}+\bar{v}^{2}+\bar{z}_{1}^{2}\right)^{\frac{5}{2}}}-\frac{\bar{z}_{2}}{\left(\bar{u}^{2}+\bar{v}^{2}+\bar{z}_{2}^{2}\right)^{\frac{5}{2}}}\right. \\
& \left.-\frac{\bar{z}_{3}}{\left(\bar{u}^{2}+\bar{v}^{2}+\bar{z}_{3}^{2}\right)^{\frac{5}{2}}}-\frac{\bar{z}_{4}}{\left(\bar{u}^{2}+\bar{v}^{2}+\bar{z}_{4}^{2}\right)^{\frac{5}{2}}}\right\} \times \overline{d r_{1}} \times \overline{d r_{2}} \times d \alpha \times d \beta \\
& \bar{k}_{z x}^{\prime}=\int_{\bar{R}_{3}}^{\bar{R}_{4}} \int_{\bar{R}_{1}}^{\bar{R}_{2}} \int_{0}^{2 \pi} \int_{0}^{2 \pi} 3 \times \bar{r}_{1} \times \bar{r}_{2} \times \bar{u} \times\left\{\frac{\bar{z}_{1}}{\left(\bar{u}^{2}+\bar{v}^{2}+\bar{z}_{1}^{2}\right)^{\frac{5}{2}}}-\frac{\bar{z}_{2}}{\left(\bar{u}^{2}+\bar{v}^{2}+\bar{z}_{2}^{2}\right)^{\frac{5}{2}}}\right. \\
& \left.-\frac{\bar{z}_{3}}{\left(\bar{u}^{2}+\bar{v}^{2}+\bar{z}_{3}^{2}\right)^{\frac{5}{2}}}-\frac{\bar{z}_{4}}{\left(\bar{u}^{2}+\bar{v}^{2}+\bar{z}_{4}^{2}\right)^{\frac{5}{2}}}\right\} \times \overline{d r_{1}} \times \overline{d r_{2}} \times d \alpha \times d \beta
\end{aligned}
$$

Thus by simple analytical differentiation all nine dimensional and non-dimensional stiffness terms can be found. Also found that three pairs of corresponding non-dimensional cross stiffness terms are equal as

$\bar{k}_{x y}=\bar{k}_{y x}, \bar{k}_{y z}=\bar{k}_{z y}, \bar{k}_{z x}=\bar{k}_{x z}$

and summation of diagonal non-dimensional stiffness terms is zero [29] as given

$\bar{k}_{x x}+\bar{k}_{y y}+\bar{k}_{z z}=0$

\subsection{Calculation of natural frequency}

Stiffness coefficients thus derived, used in force equation to find the natural frequencies. 3-DOF matrix equation is

$$
\left[\begin{array}{ccc}
\mathrm{m} & 0 & 0 \\
0 & \mathrm{~m} & 0 \\
0 & 0 & \mathrm{~m}
\end{array}\right] \times\left[\begin{array}{c}
\ddot{\mathrm{x}} \\
\ddot{y} \\
\ddot{z}
\end{array}\right]+2\left[\begin{array}{lll}
\mathrm{k}_{\mathrm{xx}} & \mathrm{k}_{\mathrm{xy}} & \mathrm{k}_{\mathrm{xz}} \\
\mathrm{k}_{\mathrm{yx}} & \mathrm{k}_{\mathrm{yy}} & \mathrm{k}_{\mathrm{yz}} \\
\mathrm{k}_{\mathrm{zx}} & \mathrm{k}_{\mathrm{zy}} & \mathrm{k}_{\mathrm{zz}}
\end{array}\right] \times\left[\begin{array}{l}
\mathrm{x} \\
\mathrm{y} \\
\mathrm{z}
\end{array}\right]=\left[\begin{array}{l}
0 \\
0 \\
0
\end{array}\right]
$$

Assuming solution of $x, y$ and $z$ as follows

$$
x=\emptyset_{x} e^{\omega t}, y=\emptyset_{y} e^{\omega t}, z=\emptyset_{z} e^{\omega t}
$$


Table 1 Algorithm for the proposed model

\begin{tabular}{ll}
\hline Steps & Details \\
\hline 1 & Load value of input parameters. \\
2 & Initiate all non-dimensional global parameter. \\
3 & Discretise all space coordinates within the interested limit. \\
4 & Run a loop for outer radius of rotor where inner radius of stator, $\bar{R}_{3}=1+\bar{R}_{2}$ \\
5 & Solve the non-dimensional force and stiffness using one iterated loop by Riemann \\
& summation followed by nested triple integral tool in any software like integral3 \\
& function of MATLAB using Eqs. (19) to (21) and (28) to (33). \\
6 & Store the maximum values for a particular interested positions in space boundary \\
& by comparing forces among different outer radius of rotor and \\
& inner radius of stator. This radius searching may be adopted any suitable method \\
& like "coordinate descent method". Store the related concern outer radius of rotor \\
& and inner radius of stator for which maximum value is obtained. \\
8 & Store the maximum values of forces and stiffness for various discretised space zone. \\
& Plot all forces and stiffness for the interested space zones. \\
\hline
\end{tabular}

Table 2 Data used for force validation

\begin{tabular}{ll}
\hline Input parameters & Values (In SI units) \\
\hline Inner radius of the rotor ring magnet & 0.005 \\
Outer radius of the rotor ring magnet & 0.024 \\
Inner radius of the stator ring magnet & 0.025 \\
Outer radius of the stator ring magnet & 0.050 \\
Length of the rotor magnet/stator magnet & $0.032 / 0.030$ \\
Mass of the rotor system & 8 \\
Load on journal/bearing & 40 \\
Residual flux density of magnets & $1.0 \& 1.2$ \\
Absolute magnetic permeability & $4 \pi \times 10^{-7}$ \\
\hline
\end{tabular}

Table 3 Data used for axial stiffness validation

\begin{tabular}{ll}
\hline Input parameters & Values (In SI units) \\
\hline Inner radius of the rotor ring magnet & 0.021 \\
Outer radius of the rotor ring magnet & 0.024 \\
Inner radius of the stator ring magnet & 0.025 \\
Outer radius of the stator ring magnet & 0.028 \\
Length of the rotor magnet/stator magnet & 0.003 \\
Mass of the rotor system & 8 \\
Load on journal/bearing & 40 \\
Residual flux density of magnets & $1.0,1.0$ \\
Absolute magnetic permeability & $4 \pi \times 10^{-7}$ \\
\hline
\end{tabular}

Putting the above the following is found as $e^{\omega t} \neq 0, t>0$

$\omega^{2}\left[\begin{array}{ccc}m & 0 & 0 \\ 0 & m & 0 \\ 0 & 0 & m\end{array}\right] \times\left[\begin{array}{c}\varphi_{x} \\ \varphi_{y} \\ \varphi_{z}\end{array}\right]+2\left[\begin{array}{lll}k_{x x} & k_{x y} & k_{x z} \\ k_{y x} & k_{y y} & k_{y z} \\ k_{z x} & k_{z y} & k_{z z}\end{array}\right] \times\left[\begin{array}{c}\varphi_{x} \\ \varphi_{y} \\ \varphi_{z}\end{array}\right]=\left[\begin{array}{l}0 \\ 0 \\ 0\end{array}\right]$

and
Table 4 Data used for radial stiffness validation

\begin{tabular}{ll}
\hline Input parameters & Values (In SI units) \\
\hline Inner radius of the rotor ring magnet & 0.010 \\
Outer radius of the rotor ring magnet & 0.020 \\
Inner radius of the stator ring magnet & 0.022 \\
Outer radius of the stator ring magnet & 0.032 \\
Length of the rotor magnet/stator magnet & $0.010 / 0.010$ \\
Mass of the rotor system & 8 \\
Load on journal/bearing & 40 \\
Residual flux density of magnets & $1.0 \& 1.0$ \\
Absolute magnetic permeability & $4 \pi \times 10^{-7}$ \\
\hline
\end{tabular}

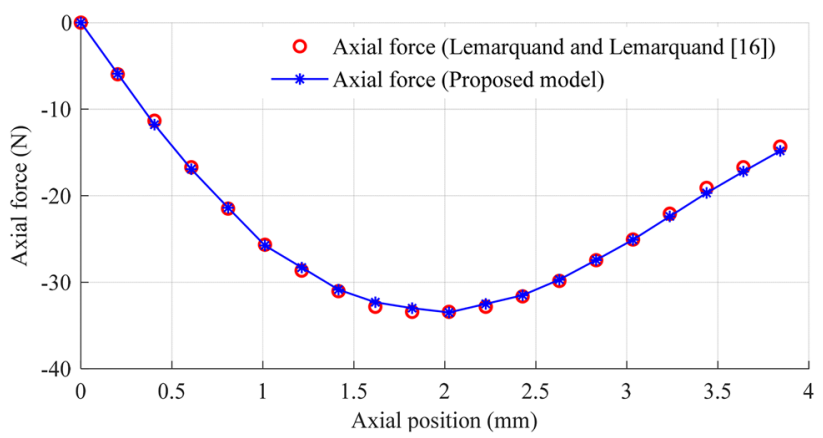

Fig. 2 Comparison of axial force computed by proposed model and ref. Lemarquand and Lemarquand [16]

$\left[\begin{array}{c}\varphi_{x} \\ \varphi_{y} \\ \varphi_{z}\end{array}\right] \neq 0$

Hence, to find the natural frequency, 


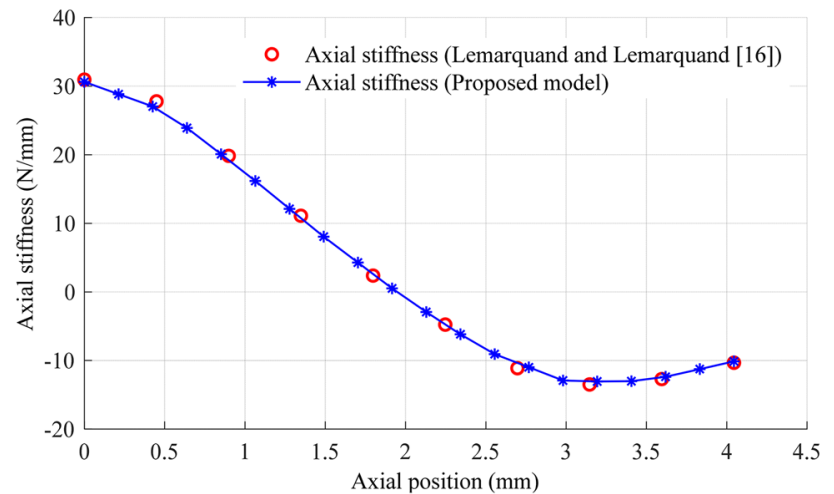

Fig. 3 Comparison of axial stiffness computed by proposed model and ref. Lemarquand and Lemarquand [16]

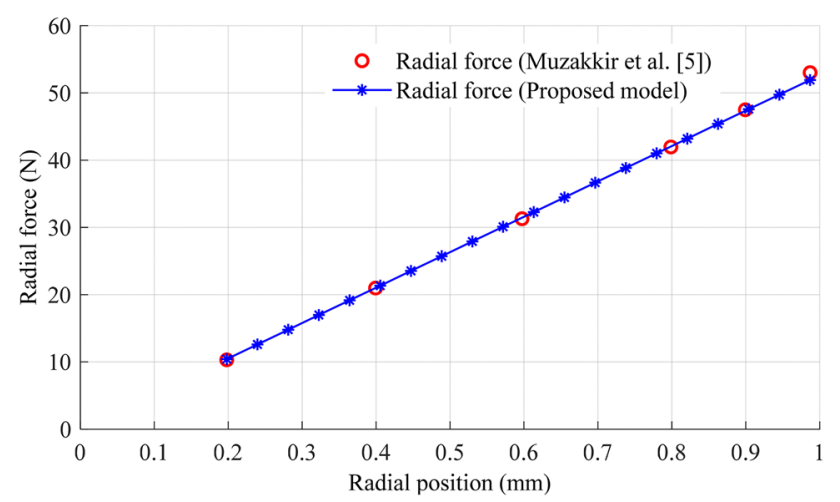

Fig. 4 Comparison of radial force computed by proposed model and ref. Muzakkir et al. [5]

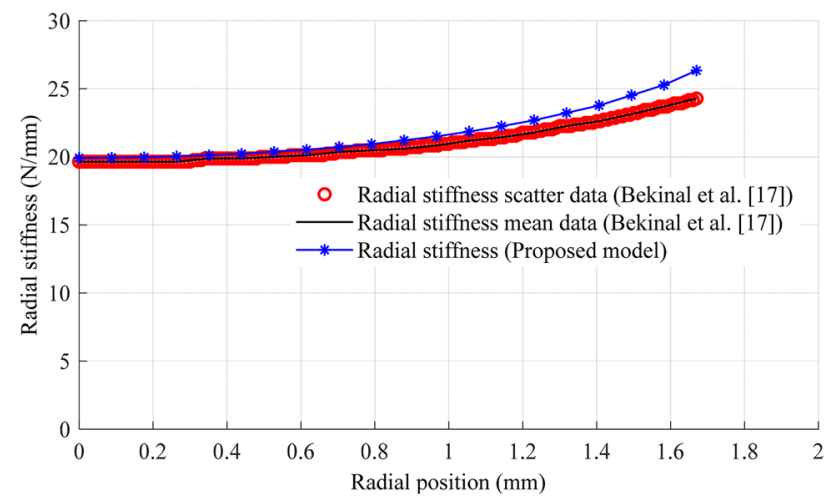

Fig. 5 Comparison of radial stiffness computed by proposed model and ref. Bekinal et al. [17]

$$
\left[\begin{array}{ccc}
\omega^{2} m+2 k_{x x} & 2 k_{x y} & 2 k_{z x} \\
2 k_{x y} & \omega^{2} m+2 k_{y y} & 2 k_{y z} \\
2 k_{z x} & 2 k_{y z} & \omega^{2} m+2 k_{z z}
\end{array}\right]=0
$$

$$
\begin{aligned}
& m^{3} \omega^{6}+4 m\left(k_{y y} k_{z z}-k_{x y}^{2}-k_{y z}^{2}-k_{z x}^{2}-k_{x x}^{2}\right) \omega^{2} \\
& \quad+24 k_{x y} k_{y z} k_{z x}-8\left(k_{x x} k_{y z}^{2}+k_{y y} k_{z x}^{2}+k_{z z} k_{x y}^{2}\right)=0
\end{aligned}
$$

Considering reference frequency [30] as

$\omega_{\text {ref }}=\sqrt{\frac{2 F_{0}}{m \delta}}$

$k_{x x}=\frac{F_{r e f}}{2 F_{0}} \times m \omega_{r e f}^{2} \bar{k}_{x x}^{\prime}$

Let $\frac{F_{0}}{F_{\text {ref }}}=S$

This non dimensional term $S$ as a ratio between applied and reference force has a typical relation with other nondimensional parameters as shown in Eq. (46).

Therefore,

$k_{x x}=\frac{1}{2 S} \times m \omega_{r e f}^{2} \bar{k}_{x x}^{\prime}$

Similarly knowing other coefficient following expression can be formed

$$
\begin{aligned}
& S^{3} \bar{\omega}^{6}+S \times\left(\bar{k}_{y y}^{\prime} \bar{k}_{z z}^{\prime}-\bar{k}_{x y}^{\prime 2}-\bar{k}_{y z}^{2}-\bar{k}_{z x}^{\prime 2}-\bar{k}_{x x}^{\prime 2}\right) \bar{\omega}^{2} \\
& +3 \bar{k}_{x y}^{\prime} \bar{k}_{y z}^{\prime} \bar{k}_{z x}^{\prime}-\left(\bar{k}_{x x}^{\prime} \bar{k}_{y z}^{\prime 2}+\bar{k}_{y y}^{\prime} \bar{k}_{z x}^{\prime 2}+\bar{k}_{z z}^{\prime} \bar{k}_{x y}^{\prime 2}\right)=0
\end{aligned}
$$

The roots of the Eq. (46) have non-dimensional Eigen values. They are generally complex conjugate. Where,

$\bar{\omega}=\bar{a}_{r} \pm \mathrm{i} \bar{\omega}_{r}, \bar{a}_{r}=\frac{a_{r}}{\omega_{r e f}}, \bar{\omega}_{r}=\frac{\omega_{r}}{\omega_{r e f}}$

where, $r=1,2,3$

For stability, non-dimensional coefficient that governs growth of vibration $\left(\bar{a}_{r}\right)<0$ and non-dimensional natural frequency $\left(\bar{\omega}_{r}\right)$ should be more than applied frequency [30].

\subsection{Input consideration for radial force maximization}

For finding maximum radial force, inner radius of the rotor ring magnet, outer radius of stator ring magnet, maximum radial clearance, same length of all rotor and stator magnet, mass of the rotating system and external applied force on rotor have been taken as input for optimization. Residual flux density of magnets is also taken as input. The space limit in $\mathrm{X}$ and $\mathrm{Y}$ direction is taken equal to positive 
radial clearance and same in $Z$ direction is taken equal up to positive axial end of the stator.

\subsection{Algorithm for the solution}

The non-dimensional space is discretised by $\mathrm{N}_{\mathrm{x}}, \mathrm{N}_{\mathrm{y}}$ and $\mathrm{N}_{\mathrm{z}}$ along $\mathrm{X}, \mathrm{Y}$ and $\mathrm{Z}$ direction. The algorithm steps as follows in Table 1.

\subsection{Input parameters}

Following input parameters are chosen to run the program for the above algorithm in the following Tables 2, 3 and 4.

\section{Validation of the proposed model}

Almost all of the available reference data are in image format. Hence to extract the force or stiffness distribution data numerically the available image information is converted to matrix data format using MATLAB image viewer. In this matrix format the data are in pixel unit. Origin position and axes position data from the available plot are also extracted. After that pixel unit is converted to axes label unit in both horizontal and vertical direction. These processed data is taken for validation with the proposed model data in statistically as well as graphically shown in Figs. 2, 3, 4 and 5. The relative error of a parameter has been calculated by subtracting the value of same parameter of proposed model from the same of reference data. The relative error is then multiplied by 100 and divided by the reference data to get the relative error in percentage. All the calculated relative error is fitted using normal distribution to obtain population mean and standard deviation. This information helps to quantify the validation statistically.

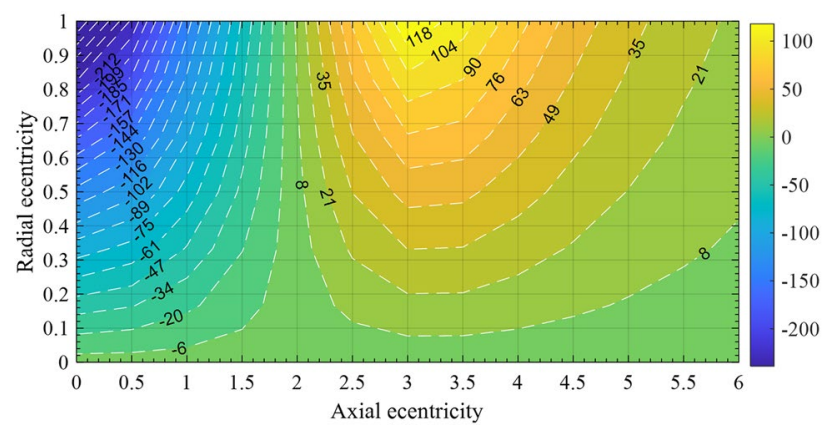

Fig. 6 Contour plot of non-dimensional radial force

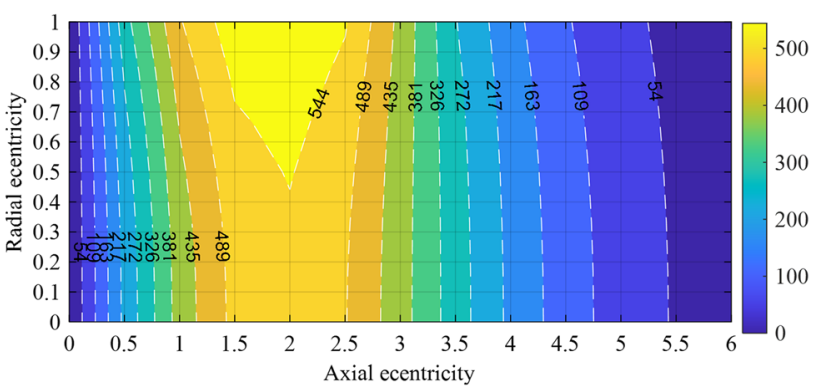

Fig. 7 Contour plot of non-dimensional axial force

\subsection{Theoretical validation for axial force and stiffness}

Ravaud et al. [12-14] and Lemarquand and Lemarquand [16] have shown the axial force variation over axial position with same relevant input data of Table 3. Axial force data with respect to axial position has been extracted from reference plot image given by Lemarquand and Lemarquand [16] linked with relevant input parameter of Table 3. The same has been calculated using proposed model. Using normal distribution population mean of relative error is calculated as $0.45 \%$ and standard deviation as $1.75 \%$ approximately. With the fitted normal distribution mean relative error of axial force using proposed model over reference model is found between -1.34 and $2.24 \%$ approximately with $99.97 \%$ confidence level. The axial force is validated by the above statistically and comparison is also shown in Fig. 2.

It is clearly observed that variation of axial force with respect to relative axial position of rotor in reported and proposed model is very close in Fig. 2 and most of the zone it is overlapped.

Lemarquand and Lemarquand [16] have shown the axial stiffness variation over axial position with same relevant input data of Table 3. Axial stiffness data with respect to axial position has been extracted from reference plot image as shown by Lemarquand and Lemarquand [16]

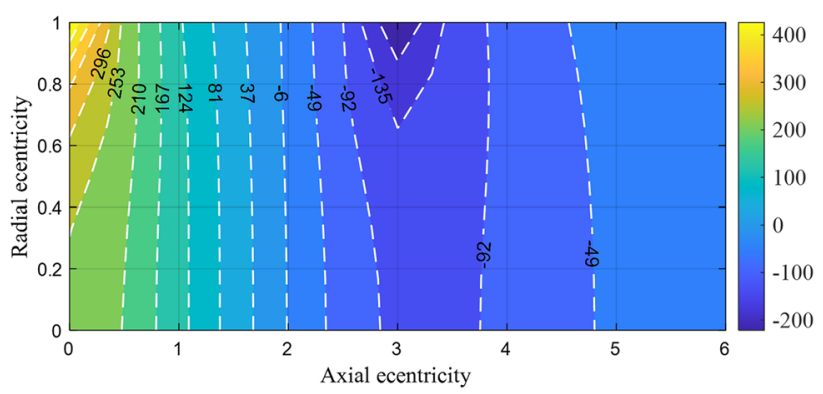

Fig. 8 Contour plot of non-dimensional stiffness $\left(\mathrm{k}_{\mathrm{xx}}\right)$ 


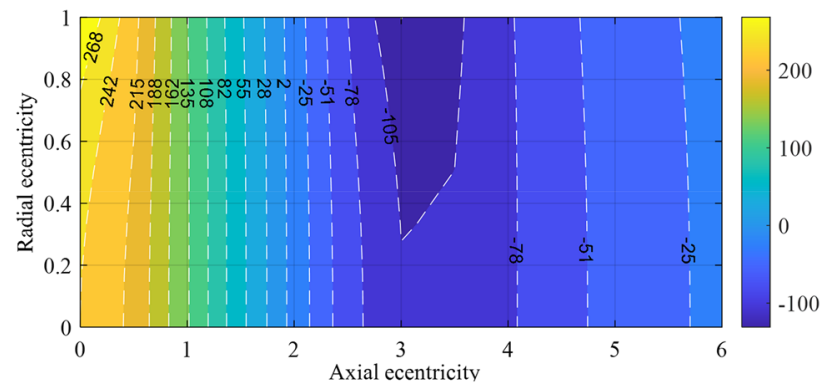

Fig. 9 Contour plot of non-dimensional stiffness $\left(\mathrm{k}_{\mathrm{yy}}\right)$

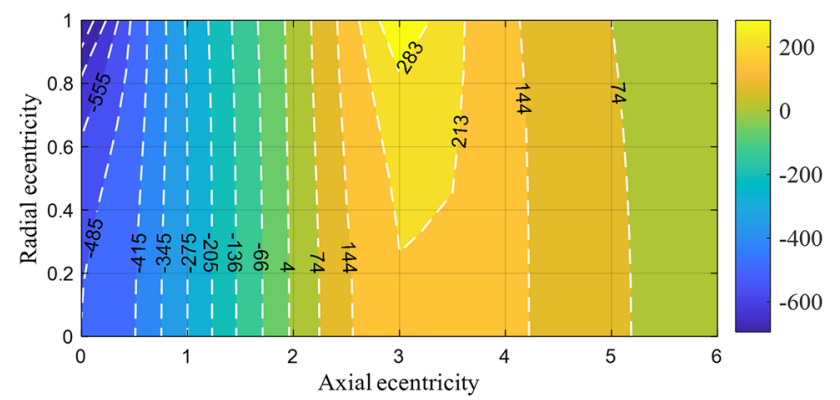

Fig. 10 Contour plot of non-dimensional stiffness $\left(\mathrm{k}_{\mathrm{zz}}\right)$

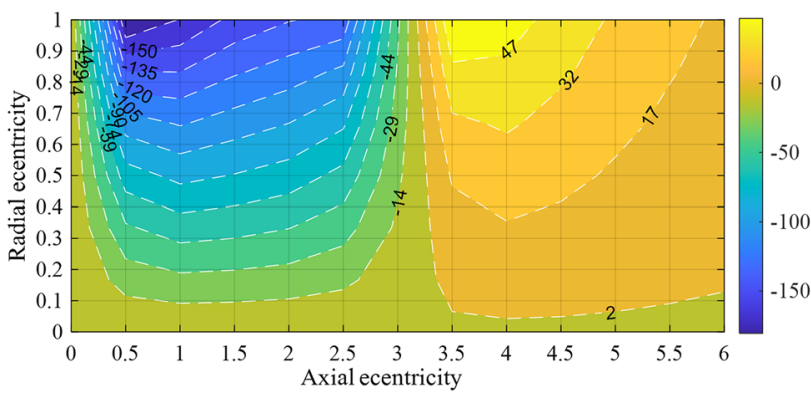

Fig. 11 Contour plot of non-dimensional stiffness $\left(\mathrm{k}_{\mathrm{zx}}\right)$

linked with relevant input parameter of Table 3. The same has been calculated using proposed model. Using normal distribution population mean of relative error is calculated as $-1.21 \%$ and standard deviation as $2.08 \%$ approximately. With the fitted normal distribution mean relative error of axial stiffness using proposed model over reference model is found between -3.27 and $0.84 \%$ approximately with $99.97 \%$ confidence level. The axial stiffness is validated by the above statistically and comparison result is also shown in the Fig. 3. Here also the results are close.

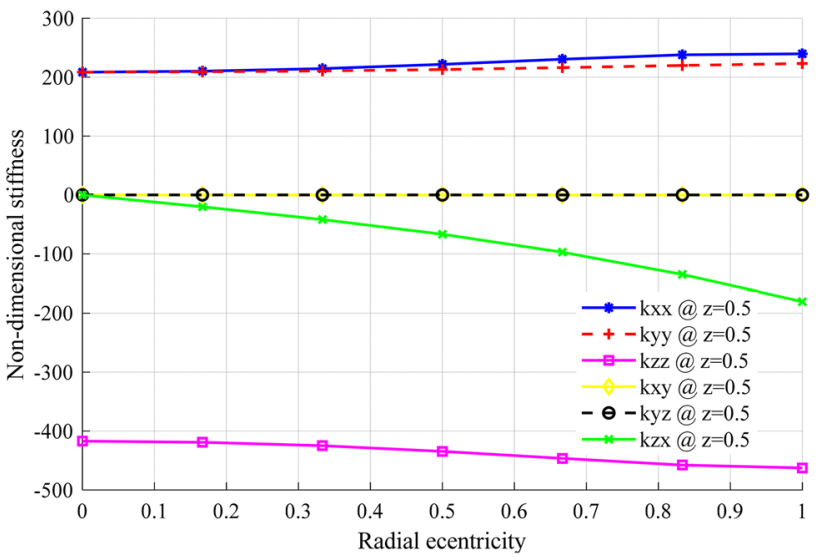

Fig. 12 Plot of non-dimensional stiffness v/s radial eccentricity at particular axial eccentricity position

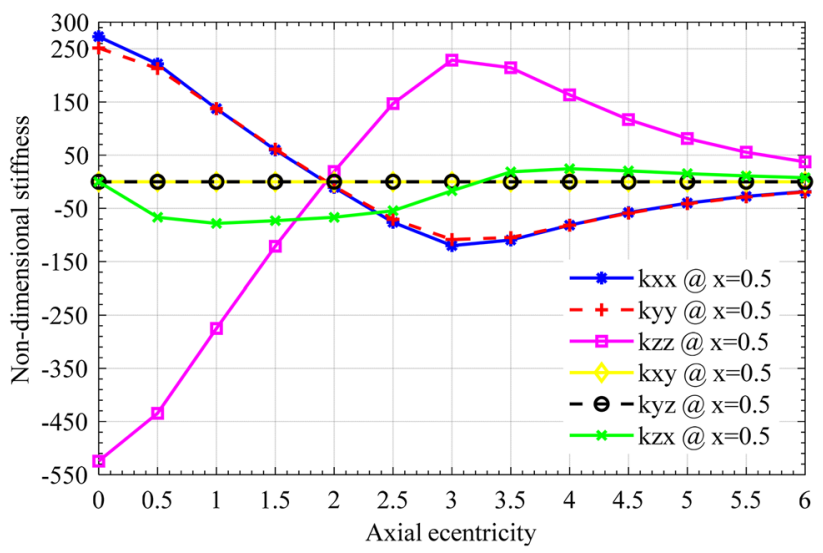

Fig. 13 Plot of non-dimensional stiffness $\mathrm{v} / \mathrm{s}$ axial eccentricity at particular radial eccentricity position

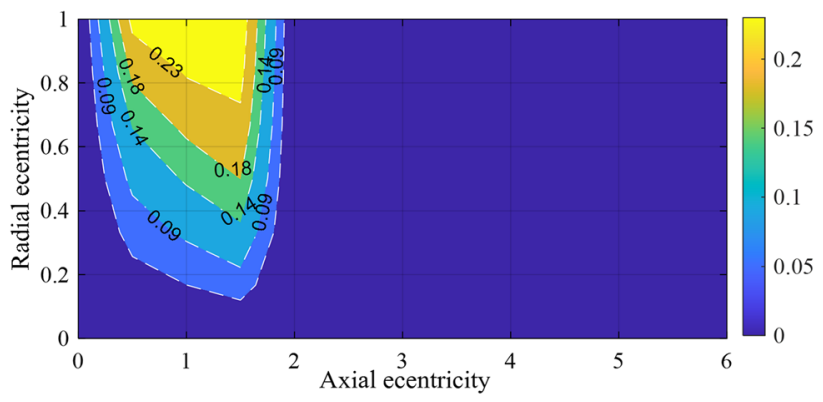

Fig. 14 Contour plot of non-dimensional 2nd mode natural frequency

\subsection{Theoretical validation for radial force and stiffness}

Muzakkir et al. [5] have shown the radial force variation over radial position with same relevant input data of 


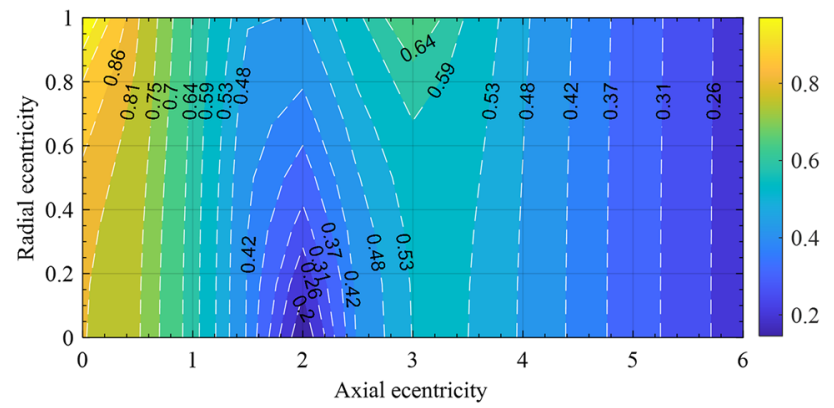

Fig. 15 Contour plot of non-dimensional 3rd mode natural frequency

Table 2. Radial force data with respect to radial position has been extracted from reference plot image as shown by Muzakkir et al. [5] linked with relevant input parameter of Table 2. The same has been calculated using proposed model also. Using normal distribution population mean of relative error is calculated as $0.12 \%$ and standard deviation as $0.70 \%$ approximately. With the fitted normal distribution mean relative error of radial force using proposed model over reference model is found between -0.57 and $0.81 \%$ approximately with $99.97 \%$ confidence level. The radial force is validated by the above statistically and comparison result is shown in Fig. 4.

Non-dimensional radial force variation is shown and validated in Fig. 4 where radial force looks almost linearly varying with the radial eccentricity position. Here also it is clearly observed that lines showing variation of radial force with respect to radial eccentricity of rotor in reported and proposed model is very close in Fig. $4 \mathrm{~b}$ and most of the zone it is overlapped.

Bekinal et al. [17] have shown the radial stiffness variation over radial position with same relevant input data of Table 4. Radial stiffness data with respect to radial position has been extracted from reference plot image as shown by Bekinal et al. [17] linked with relevant input parameter of Table 4. The same has been calculated using proposed model also. Using normal distribution population mean of relative error is calculated as $3.27 \%$ and standard deviation as $2.00 \%$ approximately. With the fitted normal

Table 5 Data used for optimization

\begin{tabular}{ll}
\hline Input parameters & Values (In SI units) \\
\hline Inner radius of the rotor ring magnet & 0.010 \\
Outer radius of the stator ring magnet & 0.040 \\
maximum radial clearance & 0.002 \\
Length of the rotor magnet/stator magnet & 0.010 \\
Residual flux density of magnets & $1.0,1.0$ \\
Absolute magnetic permeability & $4 \pi \times 10^{-7}$ \\
\hline
\end{tabular}

Table 6 Optimization results

\begin{tabular}{ll}
\hline Output parameters & $\begin{array}{l}\text { Values } \\
\text { (In SI } \\
\text { units) }\end{array}$ \\
\hline Outer radius of the rotor ring magnet & 0.030 \\
Inner radius of the stator ring magnet & 0.032 \\
\hline
\end{tabular}

distribution mean relative error of radial stiffness using proposed model over reference model is found between 1.30 and $5.24 \%$ approximately with $99.97 \%$ confidence level. The radial stiffness is validated by the above statistically and comparison result is also shown in the Fig. 5 . Here error of this parameter is little high compared to other parameters.

\section{Simulation of non-dimensional proposed model}

The non-dimensional analysis is carried out with the input parameter of Table 3.

\subsection{Non-dimensional force variation}

Contour plot of non-dimensional forces are shown in Figs. 6 and 7 in ranges of interested zone. The absolute force can be computed just by multiplying the reference force with the non-dimensional force value obtained from graph for a particular axial and radial eccentric location.

In Fig. 6, it is clear that radial repulsive force is more at zero axial eccentricity in close proximity to stator inner wall (Radial eccentricity equals to 1 ). Here, radial eccentricity and forces experienced by rotor magnets are considered positive along positive direction of $\mathrm{x}$-axis. So, negative force is directed towards negative $x$-axis, trying to move the rotor magnet away from proximity of inner wall of stator magnet and it is repulsive. It is seen at axial eccentricity greater than 1.9, force direction changes to positive one, pulling the rotor towards stator magnet and this attractive force is higher at higher value of radial eccentricity.

Figure 7 is showing maximum value of axial force at non-dimensional axial eccentricity around 2 . This is because the repulsive force (here force along positive $z$-axis) is more than that of other places as resultant of more number of axial force components between rotor and stator pole surfaces are in same direction. When rotor magnets just pass away axial eccentricity value 3 , overall two of such axial force components change the direction thus it reduces effective axial force drastically. 


\subsection{Non-dimensional stiffness variation}

Non-dimensional stiffnesses in different plane of interested space are shown in Figs. 8, 9, 10 and 11. Four nondimensional stiffnesses $\mathrm{k}_{\mathrm{xx}}, \mathrm{k}_{\mathrm{yy}}, \mathrm{k}_{\mathrm{zz}}$ and $\mathrm{k}_{\mathrm{zx}}$ are dominating as $\mathrm{x}$ and $\mathrm{y}$-axes are symmetric due to consideration of complete circular ring for the proposed model. Thus considering $y=0$, in 2D space of $x$ and $z$ axes $k_{x y}$ and $k_{y z}$ is obtained zero value for every position of that $2 \mathrm{D}$ region as seen in Figs. 12 and 13.

\subsection{Stability analysis}

The static stability is not found here as radial stiffness and axial stiffness are opposite in nature as seen in Figs. 8, 10, 12 and 13 . Hence when radial stability is achieved the axial stability loses and vice versa [28].

The stability plots are shown in terms of variation of non-dimensional natural frequency with the variation of non-dimensional angular velocity of rotor. First mode of non-dimensional natural frequency is found zero at all places. Second mode and third mode of non-dimensional natural frequency are shown in Figs. 14 and 15. If rotor is supported by rigid axial support having high stiffness value the stability may be observed at both radial and axial eccentricity 0.8 as near this point minimum of modal frequencies show high value in Figs. 14 and 15. Due to high rigid support assumption 1st mode of natural frequency also would be very high at the same point.

\subsection{Optimization results}

For finding maximization of radial forces at zero axial position, the input and output parameters are shown in Tables 5 and 6 accordingly.

This simple optimization results by one kind of iterative method and incrimination of radius per iteration after completing 4th dimensional integration of radial force as per Eq. (19) and similar portion of the algorithm of Table 1 gives the idea of stator and rotor optimum size. The iterative technique used here is coordinate descent method.

\section{Conclusions}

This paper presents a simplest method of non-dimensional modelling using simple passive magnetic bearing configuration. This model is axially not stable but it can be stable if axial outwards motion is restricted at the end of the journal with some axial shift by frictionless ball contact support just to balance axial magnetic force. Non-dimensional value of parameters are more generalised than that of parameters analysed by assuming specific dimensional values. Feasibility of actual dimensional parameters for passive magnetic bearing design can be decided using formula of reference parameters as per Eqs. (17) and (42) as well as related value of non-dimensional parameters. The yellow zone of second mode of non-dimensional natural frequency on Fig. 14 is also valuable information to the designer where the radial stability reaches the maximum as the second mode of non-dimensional natural frequency has the maximum value here. The algorithm covers one useful non-dimensional optimization of radial magnetic force. In this model any probabilistic approaches like Monte Carlo Integration method is not used so that the simulation results have deterministic information. Examples simulated in this paper act as initial guideline for permanent magnet bearing design.

\section{Compliance with ethical standards}

Conflict of interest The authors declare that they have no conflict of interest.

\section{References}

1. Yonnet JP (1978) Passive magnetic bearings with permanent magnets. IEEE Trans Magn 14:803-805

2. Yung KW, Landecker PB, Villani DD (1998) An analytic solution for the force between two magnetic dipoles. Magn Electr Sep 9:39-52

3. Simon MD, Heflinger LO, Ridgway SL (1997) Spin stabilized magnetic levitation. Am Assoc Phys Teachers 65:286-292

4. Tan Q, Li W, Liu B (2002) Investigations on a permanent magnetic-hydrodynamic hybrid journal bearing. Tribol Int 35:8-443

5. Muzakkir SM, Lijesh KP, Hirani H (2014) Tribological failure analysis of a heavily-loaded slow speed hybrid journal bearing. Eng Fail Anal 40:97-113

6. Mukhopadhyay SC, Gooneratne C, Gupta GS (2004) Magnetic bearing: an integrated platform for teaching and learning. https://www.researchgate.net/publication/228906957_Magne tic_Bearing_An_Integrated_Platform_for_Teaching_and_Learn ing. Accessed 15 Sept 2019

7. Azukuzawa T, Yamamoto S (2012) Feasibility study of a passive magnetic bearing using the ring shaped permanent magnets. Intech 44:4277-4280

8. Moser R, Sandtner J, Bleuler H (2006) Optimization of repulsive passive magnetic bearings. IEEE Trans Magn 42:2038-2042

9. Perigo EA, Faria RN, Motta CC (2007) General expressions for the magnetic flux density produced by axially magnetized toroidal permanent magnets. IEEE Trans Magn 43:3826-3832

10. Ravaud R, Lemarquand G, Lemarquand V, Depollier C (2008) Analytical calculation of the magnetic field created by permanent-magnet rings. IEEE Trans Magn 44:1982-1989

11. Ravaud R, Lemarquand G (2009) Comparison of the coulombian and amperian current models for calculating the magnetic field produced by radially magnetized arc-shaped permanent magnets. Prog Electromagn Res 95:309-327

12. Ravaud R, Lemarquand G, Lemarquand V (2009) Force and stiffness of passive magnetic bearings using permanent magnets. Part 1: axial magnetization. IEEE Trans Magn 45:2996-3013 
13. Ravaud R, Lemarquand G, Lemarquand V (2009) Force and stiffness of passive magnetic bearings using permanent magnets. Part 2: radial magnetization. IEEE Trans Magn 45:3334-3342

14. Ravaud R, Lemarquand G, Lemarquand V, Depollier C (2009) Permanent magnet couplings: field and torque three-dimensional expressions based on the coulombian model. IEEE Trans Magn 45:1950-1958

15. Samanta P, Hirani H (2008) Magnetic bearing configurations: theoretical and experimental studies. IEEE Trans Magn 44:292-300

16. Lemarquand $V$, Lemarquand $G$ (2010) passive permanent magnet bearings for rotating shaft: analytical calculation. Magn Bearings Theory Appl 5:85-116

17. Bekinal SI, Anil TR, Jana S (2012) Analysis of axially magnetized permanent magnet bearing characteristics. Progr Electromagn Res B 44:327-343

18. Bekinal SI, Anil TR, Jana S (2013) Analysis of radial magnetized permanent magnet bearing characteristics. Progr Electromagn Res B 47:87-105

19. Bekinal SI, Anil TR, Jana S (2013) Analysis of radial magnetized permanent magnet bearing characteristics for five degrees of freedom. Progr Electromagn Res B 52:307-326

20. Bekinal SI, Anil TR, Jana S, Kulkarni SS, Sawant A, Patil N, Dhond $S$ (2013) Permanent magnet thrust bearing: theoretical and experimental results. Progr Electromagn Res B 56:269-287

21. Lijesh KP, Hirani H (2015) Development of analytical equations for design and optimization of axially polarized radial passive magnetic bearing. J Tribol 137:1-9

22. Janssen JLG, Paulides JJH, Lomonova EA (2010) Analytical force and stiffness calculations for magnetic bearings and vibration isolation. Stud Appl Electromagn Mech 34:502-511
23. Wysin GM (2012) Demagnetization fields. www.phys.ksu.edu/ personal/wysin/notes/demag.pdf. Accessed 27 April 2019

24. Moser R, Barrot F, Sandtner J, Bleuler H (2002) Optimization of two-dimensional permanent magnet arrays for diamagnetic levitation. https://pdfs.semanticscholar.org/ce20/4cb8b84bb9 81fa191770f69314baa461de79.pdf. Accessed 15 Sept 2019

25. Nakum RK, Patel BS, Hadiya JP (2017) An experimental comparison of permanent magnetic bearing and deep groove ball bearing-a review. IJARIIE 3:130-135

26. Santra T, Roy D, Yamada S (2016) Calculation of force between two ring magnets using adaptive monte carlo technique with experimental verification. Prog Electromagn Res M 49:181-193

27. Santra T, Roy D, Choudhury AB (2017) Calculation of passive magnetic force in a radial magnetic bearing using general division approach. Prog Electromagn Res M 54:91-102

28. Santra T, Roy D, Choudhury AB, Yamada S (2019) Experimental verification of force and stiffness between two ring magnets calculated by monte carlo integration technique. J Inst Eng 100:123-129

29. Earnshaw $S$ (1842) On the nature of the molecular forces which regulate the constitution of the lumiferous ether. Trans Camb Philos Soc 7:97-112

30. Kramer E (1993) Dynamics of rotors and foundations. Springer, Heidelberg, pp 100-101

Publisher's Note Springer Nature remains neutral with regard to jurisdictional claims in published maps and institutional affiliations. 